\title{
ROOF TYPOLOGY AND CONSTRUCTIVE METHOD FOR THE HOUSES IN BANADKOOK-DIZE (IRAN) THROUGHOUT THE TIME
}

\author{
M. Pakcheshm ${ }^{1, *}$ \\ ${ }^{1}$ Yazd University, Art and Architecture Faculty, Imam Street, Iran - mozhgan.pakcheshm@gmail.com
}

Commission II - WG II/8

KEY WORDS: Roof Typology, Adobe Roof, Timber Roof, Constructive Method, Banadkook-Dize, Iran.

\begin{abstract}
:
Roof is regarded as one of the main components of a building and understanding how to design it by the locals throughout the time plays a key role as their answer to the structural issues and problems arising during the implementation will be helpful for the new approaches to vernacular architecture. In this study, by investigating the roof of the houses in Banadkook-Dize village in Taft county (Yazd, Iran) from the appearance of the village, the reason of form changes and their method of construction have been examined. To do this, the history of the village was divided into four different era; the first era was when the village came into existence and the villagers used to live in the citadel; the second was when the citadel had no more capacity and the people went out of the citadel to construct buildings near it; the third was the constructions after the destructive flood of 1956 in the village; and the fourth one is the current construction status of the village. Except for the first period which the citadel is almost completely destroyed and no information is left, five houses were studied for each era throughout field study and an interview was conducted with the owners. The results reveal that two general forms can be seen in the form of roof in the village, that is flat and curved roof, each of which having a different method of construction. There are different reasons involved in their changes including residents' skill in its construction, finding new building materials, keeping prices reasonable prices and responding to functional demands.
\end{abstract}

\section{INTRODUCTION}

\subsection{Banadkook-Dize Village}

Banadkook-Dize village, with its cold weather, is located on the south west of Yazd province in Iran. Through the north, the village reaches Shirkuh ${ }^{1}$ mountains and from the south, it reaches alluvial lands which is high-grade for producing Khesht (Naghsh-e Raz-e Boom, 2007). To the east and west of the village, there are some partially high hills (Figure 1).
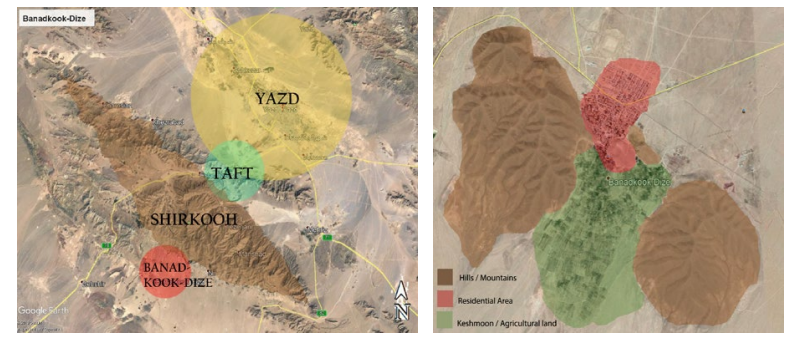

Figure 1. From left; location of the village, natural and synthetic effects in the village, author.

The houses in the village are usually made of Khesht ${ }^{2}$ and are single- or two-storey, expanding from south to north. In a

* Corresponding author

1 One of the isolated mountain systems is Shirkuh in central Iran (4050m ASL at the highest peak), west of the city of Yazd.

2 Khesht: main constituents of mud-bricks are high-grade greasy clay with full adhesiveness mixed with clean water without any harmful chemicals. As for the vast expanse of deserts in Iran, a large part of historical monuments of the country are mud-brick buildings. Among characteristics making the use of this type of mud-brick common in Yazd are: it's appropriate compatibility, its being economical as well as its easy and swift production (Nomination 1544, 2017). The most frequent building material in Iranian cultural areas has always been mud, which is available everywhere. When general classification, the village can be divided into four eras according to the changes in construction (Figure 2).

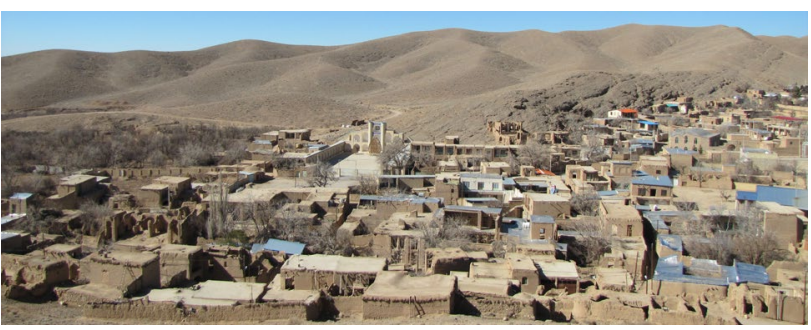

Figure 2. Village texture (the view from the top of the citadel remains), author.

\subsection{The village throughout the time}

1.2.1 The first era; life in the citadel $^{3}$ : The remainder of the citadel on top of a hill on the southwest of the village and its proximity to the Imam Zadeh ${ }^{4}$ shows the antiquity of the village (Figure 3). The reason for choosing the hill to construct the citadel

wet, it can simply be plastered on walls without shaping. Alternatively, it can be tempered and formed into large blocks with more or less rectangular side. Mud can also be manufactured into bricks and either dried (Khesht) in the sun or baked (Ajor) (Kleiss, 2011).

3 Citadels, primarily fortified country manors but also permanently inhabited defensive installations, maintained by the authorities along important land routes, and urban citadels, which functioned as administrative centres and places of refuge for inhabitants under siege. Citadels were usually erected inside walled settlements as part of the fortification process. Most citadels stand on exposed heights, with steep slopes or cliff faces serving as natural defences against approaching enemies. They have panoramic views over the surrounding land or the roads to be defended and are often within sight of neighbouring citadels. Early Iranian citadels. From the beginning of human settlement, it was necessary to defend inhabitants from enemies and wild animals (Kleiss, 1990).

4 Imamzadeh means 'offspring' or descendant of an imam. 
was seeking defense and the proximity of water (Qanat ${ }^{5}$ ), farmlands and suitable soil to produce Khesht. Unfortunately, reduction in residence in the citadel was caused erosion of it throughout the time and not much information is available about the structure and residential types (Pakcheshm, 2016).

1.2.2 The second era; life outside the citadel: After a while, the citadel residents opted for living near the hill which is regarded as the first level of village expansion. In this stage, similar to the structure of the citadel, that of the village is also dense, organic and consists of different residential types and various paths. According to the residents, the main reason of leaving the citadel was the increase in population and lack of space. In this level, the houses had one storey and were all made of Khesht.

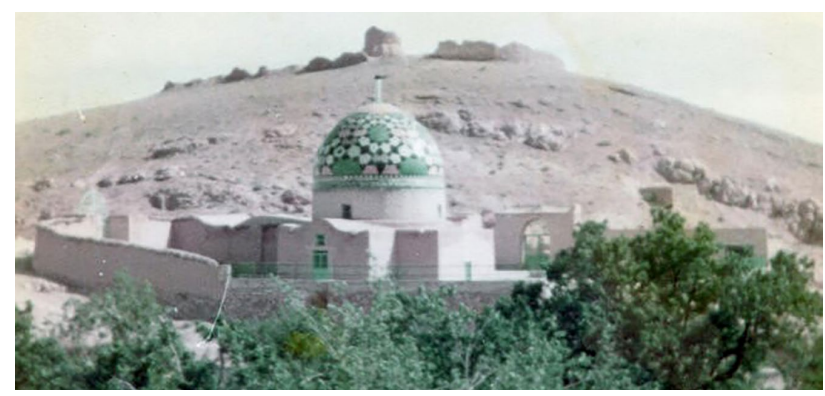

Figure 3. Imamzadeh of the village and the remains of the citadel, 1965, Banadkok.blogfa.com.

1.2.3 The third era; after the 1956 flood $^{6}$ : The flood which happened in 1956 led to the second stage of village expansion. Most of the houses in the flood path were totally or partially destroyed. Following that, some of the locals started to locate the foothills in the west of the village and set their houses on that region so as to protect their houses from flood. In this era, the houses have been all made of Khesht and have been singleor two-storey. Also, timber ${ }^{7}$ has been used to reinforce the adobe structure and make the buildings light.

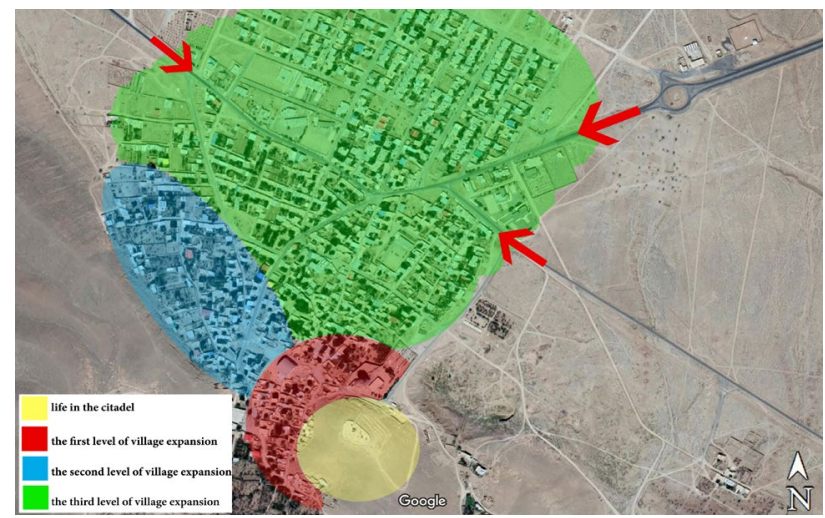

Figure 4. the village throughout the time, author.

5 Throughout the arid regions of Iran, agricultural and permanent settlements are supported by the ancient qanat system of tapping alluvial aquifers at the heads of valleys and conducting the water along underground tunnels by gravity, often over many kilometres. The qanats provide exceptional testimony to cultural traditions and civilizations in desert areas with an arid climate (Nomination 1506, 2016).

6 The flood, known as the Black Flood, occurred in the summer of 1956 in the city of Taft and surrounding villages (Ayatizade, 1956).

7 The residents are mostly farmers, planting almond, walnut and cottonwood trees to use the wood in their houses (Pakcheshm, 2016).
1.2.4 The fourth era; contemporary life: In the third stage of expansion, the village moves towards the north. In this stage, the structure of the village is mostly based on nonlocal materials and the residents utilized modern approaches and materials for construction. The houses are mostly two-storey, built with bricks, girders and block joists (Pakcheshm, 2016) (Figure 4).

\subsection{Research Methodology}

In order to achieve the main aim of the research, that is to analyse roof typology of the houses in Banadkook-Dize, bibliographic research, field research and interviews were used. In field research, due to vastness of the village and necessity of identification of all the varieties, the village was divided into three parts based on the stages of expansion of the village which was done in several weeks of visiting and photo taking. Also, the interviews were conducted so as to identify the methods of implementation, the lifestyle and the changes in the village throughout the time. Finally, a descriptive-analytical approach was used to investigate the information and classify the general forms and their constructive methods.

\section{MAIN BODY}

In this part, the studies related to the roof of the village houses in the second, third and fourth era will be described. The first era which explains the constructions inside the citadel is not described here due to the fact that the citadel has been destroyed and there was not enough evidence.

\subsection{Roof of the houses in the second era; outside the citadel}

In this era, houses usually had one storey and were made of Khesht. The villagers used the alluvial soil near the citadel to produce Khesht. The insufficient size of the houses at the beginning of the era was because the residents did not need a bigger space and the structure of the village was dense as residential citadel. It helps to the stability of adobe structure and neutralizing the lateral forces. In fact, the main problem in constructing vaults is how to transfer of the outward thrust force at the bottom to the supports and foundations (Minke, 2006). Therefore, the density of the residential fabric will help to transfer the outward thrust force to the ground ${ }^{8}$. Over time and by increase in residents' skill in construction and the need for bigger spaces, the form of the roof has changed. At the beginning, the spaces were covered with 'Chahar-dori vault' (second type of Kolombu' -four laps ${ }^{10}$ ) and after some time, with 'Barrel vault ${ }^{11}$. Currently, Chahar-dori vault is mostly seen in the livestock spaces or depots. The reason is that the residents have changed the function of the previous vault as they have built Barrel vault (Figure 5).

8 In one or two-storeyed buildings, the principle danger during earthquakes is that walls will fall out and roofs will come down. Therefore, one of the main structural tasks when designing earthquake-resistant buildings is to ensure that walls do not fall out (Minke, 2006).

9 Kolombu vault: is executed between arch and because of its domelike shape occasionally is mistaken as a dome. Usually Kolombu vault has a square base with rare cases of rectangular base. Due to its simple execution, light weight and resistance against earthquake, it is widely used particularly in bazaars. The curvature of Kolombu vault is mostly part of a circle with a few cases of ecliptic curves. The apex of the arch is either obstructed with bricks or transformed into an oculus by installing a skylight at its top. Kolombu is installed using two methods of Gerd-chin or multiplex (Nomination 1544, 2017).

10 This vault is one of the most important Iranian vaults and belongs to the Sasanian Empires (Sadat Etezadi and Rahimi Ariaei, 2015).

11 The vault is a parallel series of arches used to form a roof, the most common form being a cylindrical or barrel vault. 

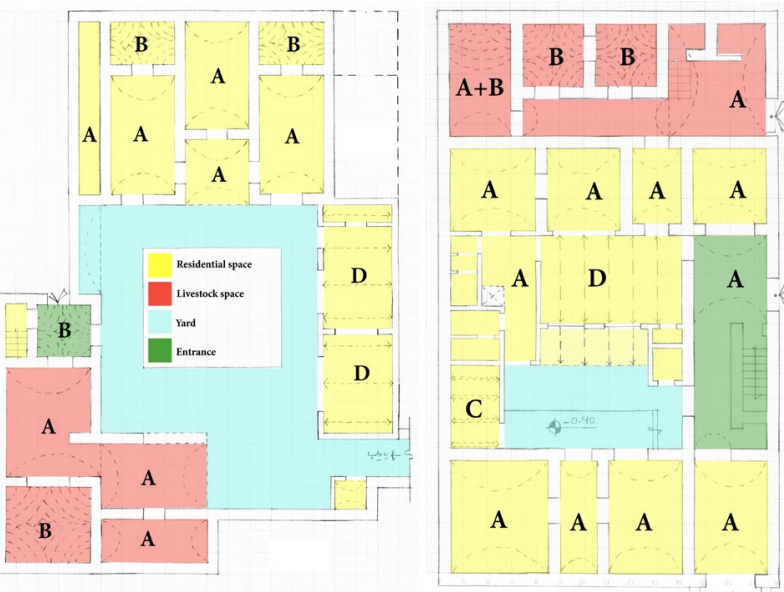

Figure 5. two examples of study houses, you can see the Chahar-dori vault, which is mostly used for service and livestock spaces, (A: Barrel vault, B: Chahar-dori vault,

C: Takhte-Poosh, D: Girder and Zarbi vault), author.

2.1.1 From Chahar-dori vault to Barrel vault: Chahar-dori vault is usually implemented on a square plan. The centre of each side of the square is found and the resulted triangle on each side is covered with a large squinch to the hypotenuse (Memarian, 2016). This roof is stable due to its semicircle shape and force transfer is done similarly onto all four walls. This roof has some limitations, including:

1.Due to the final height of the roof, it is not possible to build another floor on top of it because flattening the roof will be difficult and futile.

2.The four walls under the roof are bearer's wall and not many doors and windows can be placed in it; as a result, the quality of the space and the relationship of the spaces with each other will reduce (Figure 6).
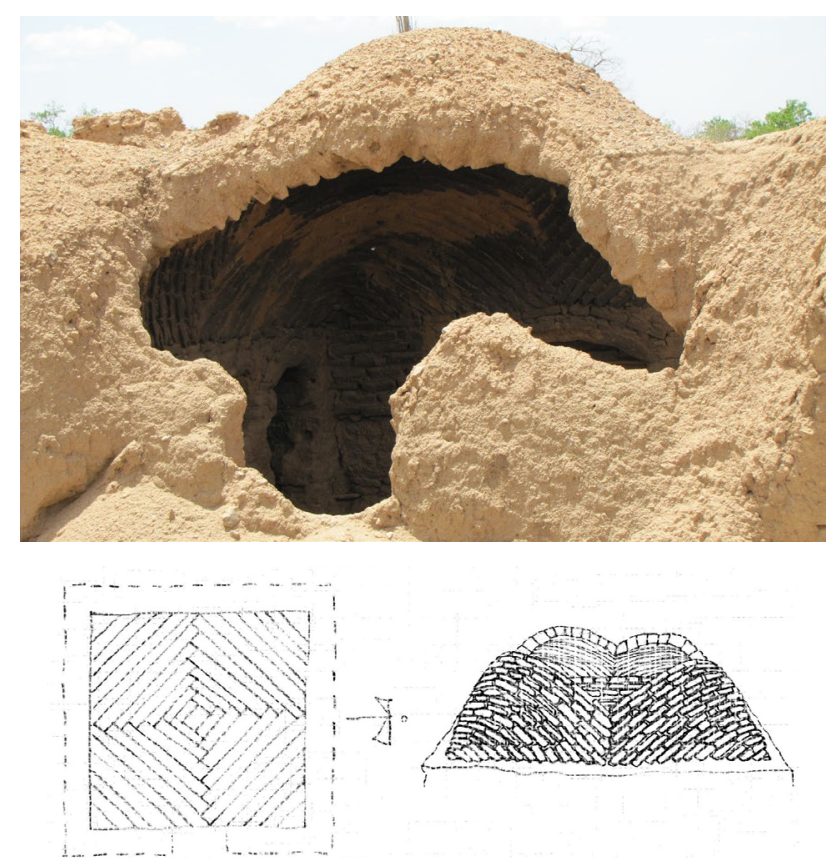

Figure 6. Chahar-dori vault executed in a livestock space, author.

At the beginning, the villagers set up their houses by repeating the square modules with Chahar-dori vaults. By increasing the number of people in the house and the need for larger space with better quality, the square plan of the spaces was changed to the rectangular one (Figure 7). In the rectangular plan which is covered with Barrel vault, only two walls are bearer and the other two are espars or not bearer ${ }^{12}$ (Figure 8). There are some methods to implement this vault which is defined by the placement of the Kheshts. The methods are Zarbi, Roomi or Herreh, and Chapileh (Figure 9).

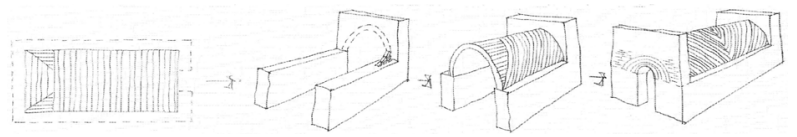

Figure 7. How does the Barrel vault run? author.

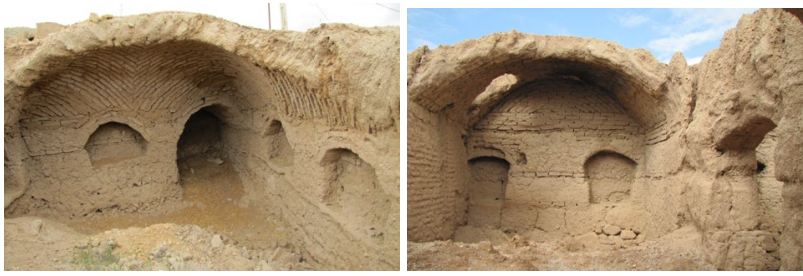

Figure 8. From left; Combination of Chahar-dori vault and Barrel vault, espar wall and Barrel vault, author.
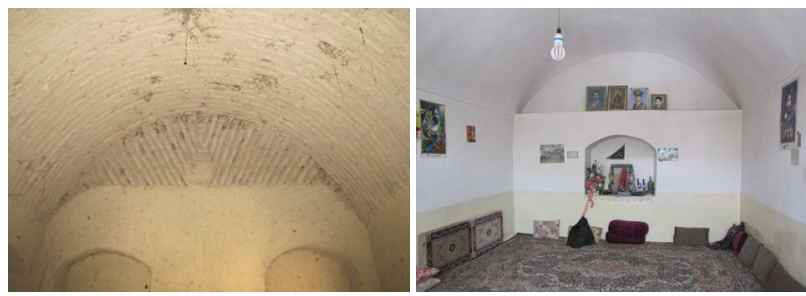

Figure 9. The Barrel vault executed in a residential space, author.

2.1.2 Zarbi brickwork vault ${ }^{13}$ : in this method, one of the espar walls are worked until the final height. The shape of the vault is then implemented on it by the gypsum ribbed vault

12 Walls of the historic city of Yazd buildings are of two types: bearing or non-bearing. Bearing walls which are also called 'piers' transfer the load of roof to the foundation and into the ground. There exist non-bearing walls which have the function of separating or protecting against adverse weather conditions. These walls are divided into transparent and nontrans parent ones. During the construction of walls, firstly the bearing ones are erected followed by espars after the initial subsiding of earth. The large diameter of walls particularly mud brick walls are intended for bearing loads and haltering the repulsive force of the ceiling. Those parts which bear more loads subside more resulting in cracks appearing on walls. Thus, in order to prevent this, niches are installed at certain heights of the wall so it is normal that in the majority of thick walls, the number of niches increase as well (Nomination 1506, 2017).

13 Tāq-e Zarbī is used to roof rectangular buildings in areas where wood is rare, notably in central Iran. A remarkable feature is that these vaults are constructed without the aid of cantering. Most often the unbaked bricks are laid up obliquely in successive laminae through the length of the building and leaning against a vertical wall at the back. The vault may also include a semidome at one end or may be built from each end and finished in the middle with courses of bricks laid perpendicular to the preceding ones. These bricks are very carefully mortared with a mixture of mud and lime. The barrel vaults are plastered with mud on the interior as well as on the exterior, so that their structures are rarely visible; such a roof is sometimes even completely hidden from view on the exterior by a second, flat roof constructed above it as protection against deterioration caused by rain and snow and as a useful space for sleeping during the summer (Bromberger, 1988). Zarbi or par execution is less resistant and less bearing than the Roomi vault but because of its simpler method of construction, it is more widespread than the Roomi vault and is appropriate for medium-sized spans (Nomination 1506, 2017). 
(gypsum Tavizeh ${ }^{14}$ ) and the Khesht are leaned on the espar wall from their $20 \times 20$ width and the vault are continued until the end. In sorting the Kheshts of each row, it is tried that the spaces between the Kheshts in each row do not oppose each other and hence improve the sustainability of the vault. It is also to be mentioned that where the bearer walls reach the vault, they have one fewer Khesht so that the vault can settle on the wall and stabilize (Figure 10).
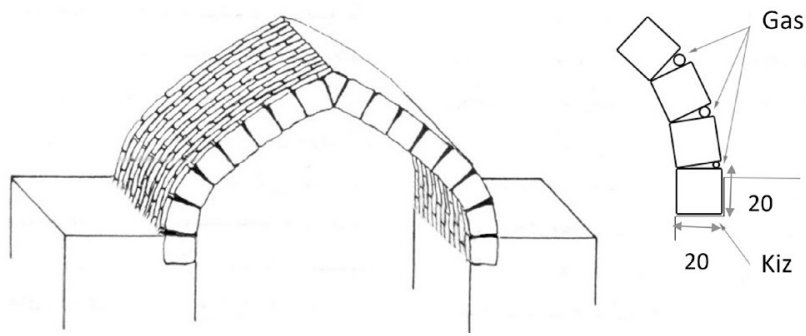

Figure 10. Zarbi brickwork vault, Gas: Brick crumb to reinforce the vault, Kiz: vault base, (Pirnia, 1995).

2.1.3 Herreh brickwork vault ${ }^{15}$ : in Herreh method, the Kheshts are implemented from the $20 \times 5$ dimensions on the bearer wall. It should be started from both sides so that the Kheshts are locked into each other in the middle of the vault. In this implementation, as the roof moves along the wall, no Kiz is needed on the bearer wall. In this condition, a gypsum tavizeh can be used for more accurate implementation (Pirnia, 1995).

2.1.4 Chapileh brickwork vault ${ }^{16}$ : in Chapileh method which is useful for spaces with small spaces, Khesht is used from $20 \times 20$ width in a way that the same dimension of the Khesht is visible from the bottom. Due to the thinness, this vault is fragile and is not bearing bearable (Pirnia, 1995) (Figure 11).

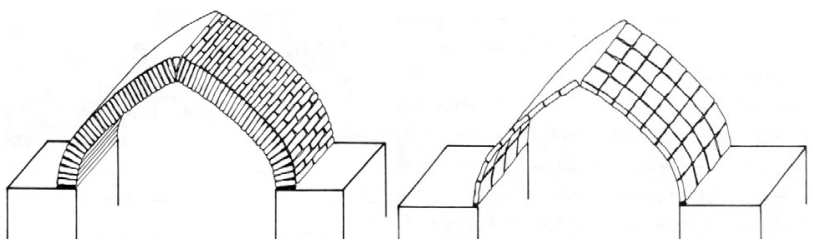

Figure 11. From left; Herreh brickwork vault and Chapileh brickwork vault, (Pirnia, 1995).

Over time, the villagers first covered their rectangular spaces using Chahar-dori vault and Barrel vault and after gaining enough skill in Barrel vault, they just implement this vault. It is to be mentioned that in implementing the Barrel vault, the three mentioned methods can be combined (Figure 12).

14 The meaning of tavizeh is the sunbow and a curved branch. Tavizeh in architecture is the listel of the carrier arches that is made by carrier Chafd. This listel of arch can support major openings that cannot be easily arched. In fact, it can be said that tavizeh is a curved timber that is implemented by building materials and its function is to bearing the whole weight of the roof whether in flat or curved form (Ebrahimi and Aniran, 2015).

15 Roomi or Herreh execution is very resistant and is used in wide spans because of its high capacity for bearing (Nomination 1506, 2017).

16 Chapileh has a low resistance but is built more rapidly. Therefore, it is mostly used in lintels or in small spans which are less bearing. But in order to increase its resistance it is usually implemented in several layers (Nomination 1506, 2017).
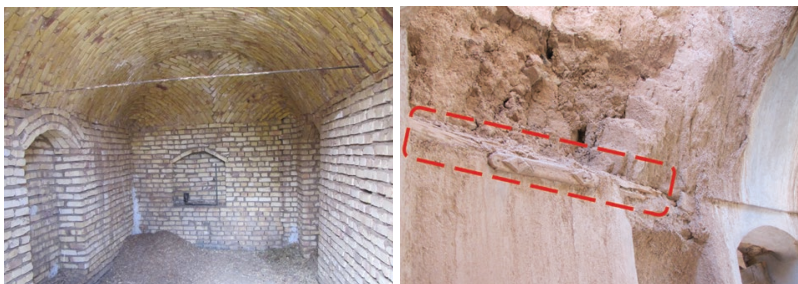

Figure 12. From left; the brick Barrel vault, begin to use wood at the base of the vault, author.

\subsection{Roof of the houses in the third era; after the 1956 flood}

As it was said, there was a destructive flood in 1956 ruining many houses. The villagers choose the western hills to build new houses to prevent another flood. However, there was less area so the houses were built in two stories where the ground floor is covered with Chahar-dori or Barrel vault and the first floor is covered with timber. Timber ${ }^{17}$ was used so as to increase the construction speed and making the building lighter. Usually, the wood from almond, walnut and cottonwood tree were used as they were planted there (Figure 13). The wooden covers in village houses will be described below.

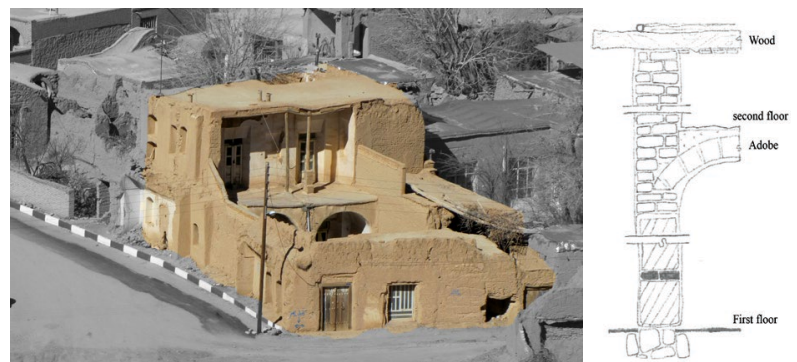

Figure 13. The wall section of one examples of study houses in the third era, author.

2.2.1 Takhte-Poosh ${ }^{18}$ : After finishing adobe walls on the first floor, two main wooden bars, known as 'Palar' were used

17 Another building material was wood, from both coniferous and deciduous trees, especially poplar; it is still important today for supports and roof construction in the traditional rural architecture of Persia. Roofs and ceilings are constructed of logs, across which smaller wooden boards are laid and on top of them reed mats or thatch; the whole is then covered with mud, which has first been levigated and tempered with straw, for 'insulation'. (Kleiss, 2011).

18 The roof type mainly in use on the Iranian Plateau, particularly on the slopes of the Zagros mountains, is the flat roof. Ceiling joists are placed on top of the walls and for the open porch over heavy beams supported by columns. Ceiling boards are placed over the joists, or instead, light ceiling battens are nailed across them and are covered with braided reed mats. A mixture of mud, straw, and some lime, well worked and rather soft, is spread over the ceiling boards or reed mats respectively in many thin layers. Each layer is given some time to dry after which it is compacted with a rolling stone. The spreading of these layers is continued until the roof reaches a thickness of about 10 inches in Fārs and Isfahān, and about 20 to 25 inches in Āzarbaijan, where the mud-lime mixture, however, contains a much larger proportion of straw. Great care is taken during the spreading process that the roof is divided into sections 10 to 12 feet wide by moulding the mud mixture into channels, slightly depressed in the middle of the roof and deepening toward the edges, where they end in wooden spouts. After each rain the roof has to be compacted with the stone roller; otherwise, it would develop cracks while drying. The stone roller remains on the roof. Snow has to be removed immediately, since melting snow penetrates faster than rain. Apart from these maintenance precautions, the mud roofs serve a good purpose in keeping the rooms cool in summer and warm in winter. During the construction of the roof ample salt is strewn on the mats and mixed with the mud to keep insects, in particular white ants and borers, away (Anderson, 1991). 
and were located on the wall as bearer bar. Then, the minor wooden bars, 'FreSeb' were placed on the main bars with a 50$80 \mathrm{~cm}$ distance and the empty space in between was covered with wooden boards of $3-5 \mathrm{~cm}$ thickness. Mud were used to cover the pores in the roof (Memarian, 2016) (Figure 14).

It should be noted, the overall dimensions of the wooden covered areas in the village are not large. There are some reasons for this:

1. No need for a bigger space.

2. Lack of appropriate wood for the roof; due to its length and high resistance, cottonwood tree is the best option to cover the roof. However, it cannot be found abundantly in the village and only the affluent wealthy people in the village who worked in the gardens near the village could afford it.

3. Dependence of space length to wood length; when using a wood, 40 to $50 \mathrm{~cm}$ should be outside the roof. The reason is to remove the hidden humidity in the wood by wind. If the wood was used completely in the roof, the possibility of dry rot might increase. So, the useful length of the wood will increase as some parts are outside from both sides, hence the length of the space will decrease.
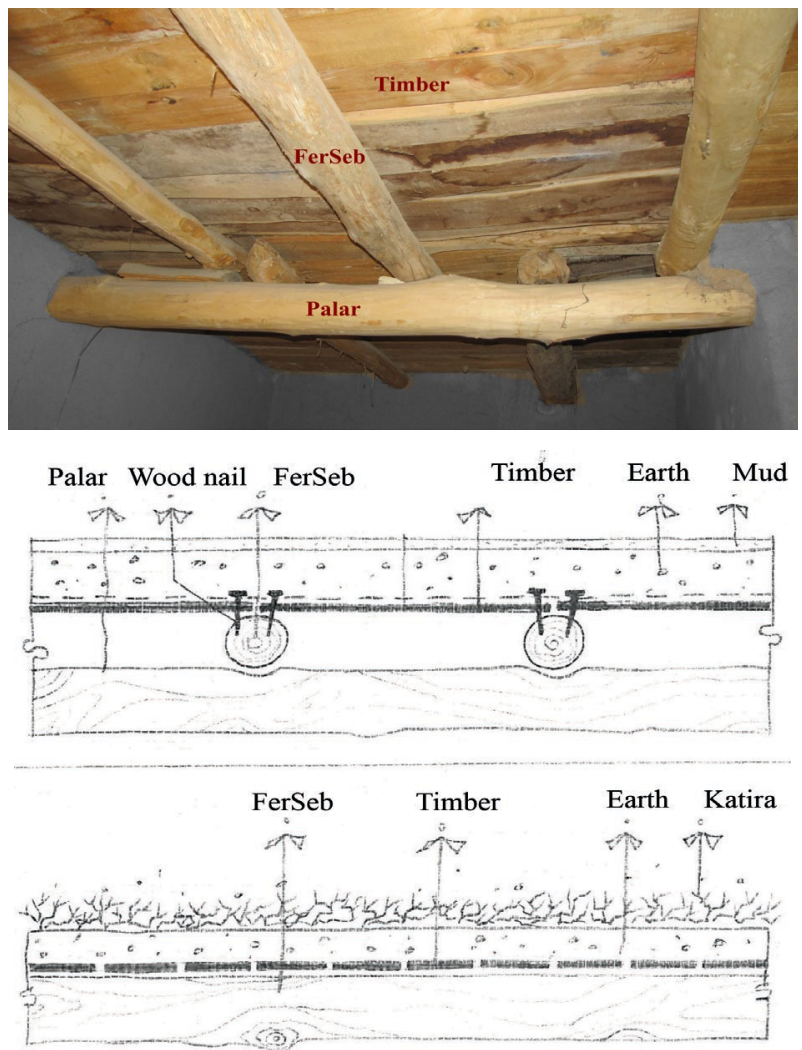

Figure 14. How does the Takhte-Poosh run? The natives use mud and salt to prevent water from penetrating the roof. Katira is also used for reinforcement at the edge of the walls, author.

2.2.2 Varde-Poosh: Like the previous method, in this one the major and minor bars are placed in their own places and leaves of trees are used harmoniously to cover the space between minor bars. This method is mostly used for insignificant spaces such as stables or spaces with small craters such as first floor terraces where minor bars are not implemented from time to time (Pakcheshm, 2016) (Figure 15 and 16).

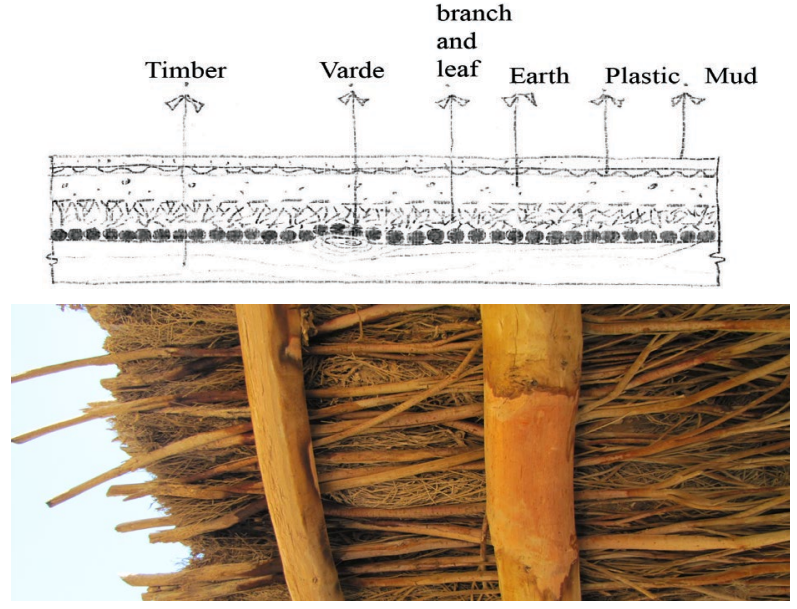

Figure 15. How does the Varde-Poosh run? In some houses, plastic is used as anisogamy, the mat is also used on wooden roofs, author.
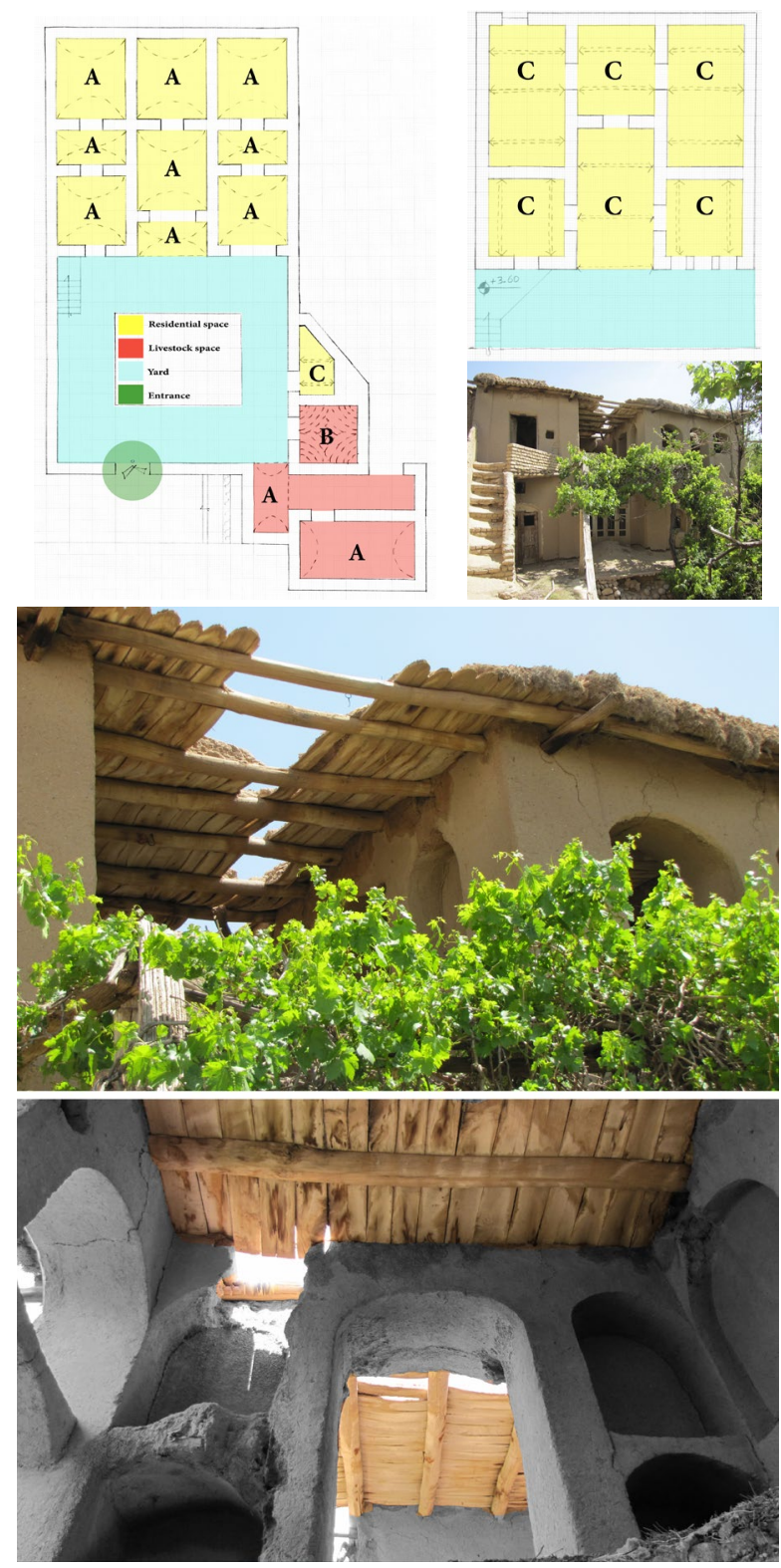

Figure 16. one examples of study houses in the third era, (A: Barrel vault, B: Chahar-dori vault, C: Takhte-Poosh), author. 
2.2.3 Konu-bandi ${ }^{19}$ : In two-storey houses, the roof of the ground floor should be flat so as to make it usable, therefore, Konu-bandi is used. In this method, instead of filling the gap between the two vaults and making the roof heavy, adobe or brick is used and the surface is flattened. This, in both twostorey and one-storey house with the ability to use the roof reduces the rainfall to the foundation of the vaults and increases the durability of the roof (Figure 17).

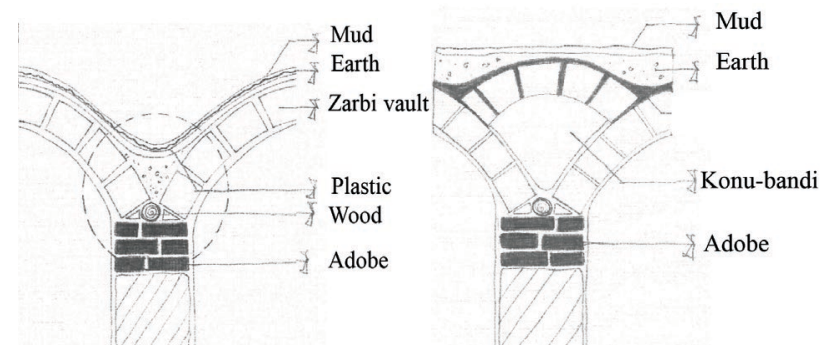

Figure 17. How does the Konu-bandi run?, author.

\subsection{Roof of the houses in the fourth era; contemporary times}

Recent developments in most rural regions of Iran, the sequence of construction operations has changed profoundly during the last thirty years; traditionally materials were manufactured and prepared in situ, whereas today they are purchased in industrial production centres that are sometimes quite distant.

Baked bricks and cement have become the predominant construction materials, almost completely displacing unbaked mud. The growth of cement production, in response to strong demand in both urban and rural markets, has been particularly spectacular (Bromberger, 1988).

In rural areas traditional construction linked the mason, assisted by several helpers, on one hand, and the family and friends of the client, on the other. These last took care of the less specialized work, such as transport and preparation of certain materials, levelling the ground before construction, digging the foundation trenches, and so on, whereas the mason performed the more skilled tasks, such as raising the walls and constructing the vaults. In fact, the development of construction since the 1950s is a good indicator of the changes that have affected Iranian society during the last three decades; the demographic explosion and swelling of the urban population, westernization of technology, and disappearance of traditional skills (Bromberger, 1988).

Unfortunately, earth as a building material has lost its credibility chiefly because most modern houses with earth walls cannot withstand earthquakes, and because earth is viewed a building material for the poor (Minke,2006).

Therefore, nowadays due to the prevalence of urban construction methods (centre of the province) in the village and lack of enthusiasm to create adobe buildings, houses are normally made of brick and the roof are implemented with girder and block joists. Moreover, to use the spaces on the roof, metal inclined roofs have been implemented in some houses. (Figure 18 and 19)

19 Konu-bandi is executed in many vaults in order to adjust the height of vaults and to flatten the surface of rooftops. Also, another advantage of Konu-bandi is thermal insulation of the ceiling. Ordinarily the construction technique of Konu-bandi is Qomi-Poosh (Nomination 1506, 2017)

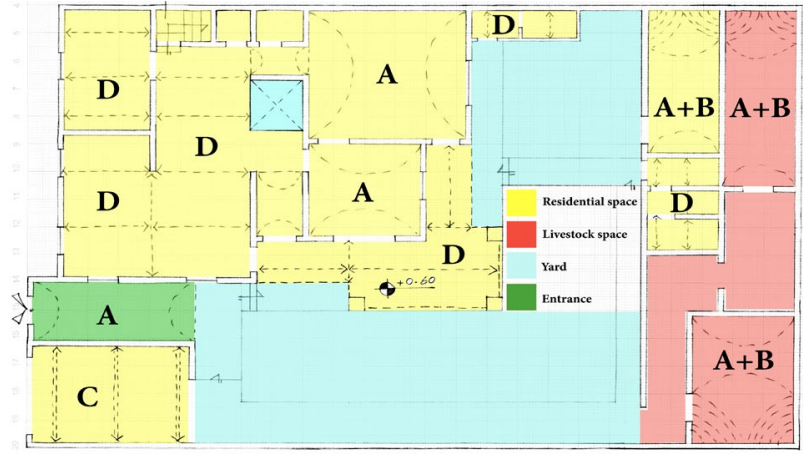

Figure 18. One example of houses in the fourth era, houses in this period are usually a combination of several modes of construction, some over time, (A: Barrel vault, B: Chahar-dori vault, C: Takhte-Poosh, D: Girder and Zarbi vault), author.

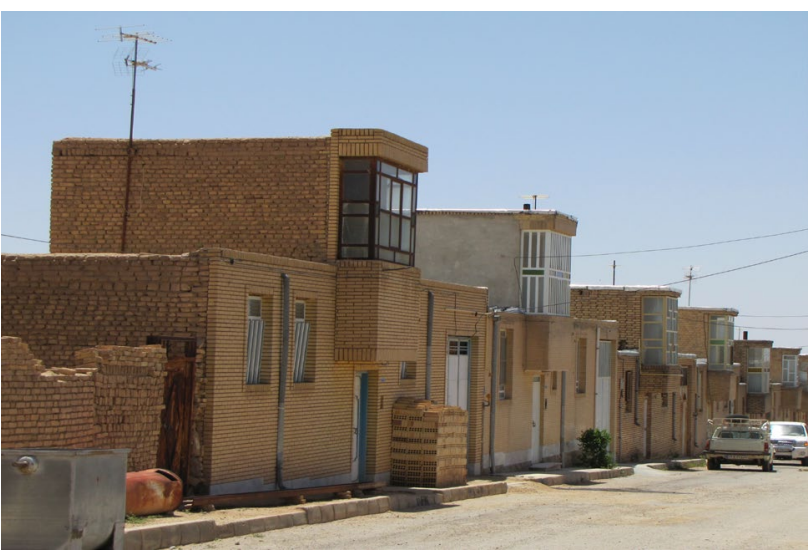

Figure 19. New texture of the village, author.

2.3.1 Girder and Zarbi vault: In this method, girders are placed on the bearer wall with an 80 to $100 \mathrm{~cm}$ distance with each other. Then bricks and a combination of gypsum and soil, small vaults can be implemented between the girders. Finally, mud (Kah-gel ${ }^{20}$ ) is used to flatten the roof. This vault is called Zarbi (like an in Figure10) because of the placement of the bricks, the $10 \times 20$ dimension of which is used (Pakcheshm, 2016) (Figure 20).
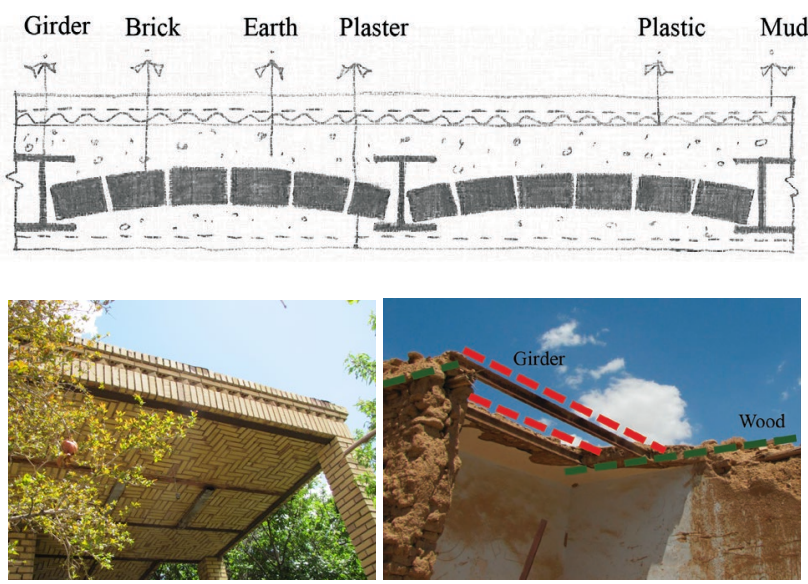

Figure 20. Girder and Zarbi vault, sometimes wood was used instead of the girder, author.

20 Kah-gel is a mixture of levigated earth, water, and chopped straw, which is vigorously kneaded with the bare feet (Bromberger, 1988). 
2.3.2 Block joist: In this method, joists-trusses were implemented with a 40-to-50 distance with each other on the bearer wall and clay or cement blocks are used to cover the distance between the joists. This method is totally nonlocal and is common in most parts of Yazd province due to its easy access to materials and fast implementation. (Figure 21)
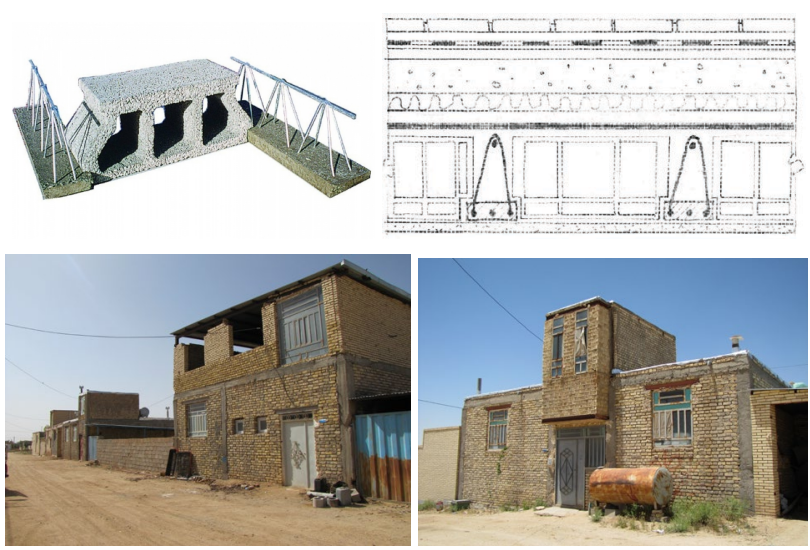

Figure 21. From up; Block joist, two examples of contemporary houses, author.

\section{CONCLUSION}

The rural architecture of Iran is an efficient and thoughtful example of the architecture in harmony with the everyday life of people, natural environments, and respect for nature. There are many positive principles, standards and fields in Iranian rural vernacular architecture that, if considered in new housing plans, can contribute to formation of a proper fabric (Sartipipour, 2012).

Promotion of new patterns and copying them into rural life and housing, the shrink of land lots, and domination of urban standards in residential density, structures and techniques are problems affecting rural housing. Moreover, neglecting vernacular technologies and ignorance toward the vernacular values and identity have led to a new pattern of housing seen everywhere; patterns that are sometimes in contradiction with vernacular patterns. They are neither a precise imitation of foreign patterns nor a proper application of new materials and technologies; they are neither in harmony with the environment nor are they compatible with the present needs of the residents ( Sartipipour, 2012) Accordingly, it is necessary to study the formal changes in rural areas, especially the study of changes in the final coverage of houses as the most obvious part of it in the general view of the village.

Roofs have been constructed in a wide variety of forms (flat, pitched, vaulted, domed, or in combinations) as dictated by technical, economic, or aesthetic considerations. This article attempts to study the different types of roof form based on its construction in the village of Banadkook-Dize. The Type is known in typology as representing a group of architectural organs. In fact, in typology of an architectural component, in addition to its formative changes, the reasons and factors behind these changes must also be explored in order to allow for more accurate classification (Memarian, 2015). The necessity of typology is that it helps us to get a systematic understanding of the architectural realities of a place. Typology can bring us closer to the mental map of past architects and see and experience architecture in a similar way. Moreover, this paper examined the reasons for the change in the roof type through time, which is summarized below.
Environmental reasons: Environmental changes and lack of easy access to vernacular materials such as quality wood or suitable soil with the right granulation have reduced the tendency to use these materials. Also, finding new vernacular materials or replacing non-native materials (common and cheap materials in today's market of cities) in the construction process are other factors. Heavy rains and damage to earth buildings have also been identified as a deterrent to the use of traditional roofing methods.

Socio-economic reasons: The financial ability of the villagers over time has been one of the most important factors in choosing the type of roof. Because some methods require high skill to perform, which only a professional architect can do, and the residents of the house have not been able to perform it, then other methods are chosen.

Today, with the relative increase in the financial capacity of the villagers and the desire for new construction methods, the roofs of the village houses are mostly flat (like urban houses). Also, a change in the lifestyle and function of the spaces, which has changed the shape and dimensions of the spaces, and as a result, some of the roofs cannot be implemented.

Technical and executive reasons: Increasing the builder skills in construction methods is one of the reasons for the change in the roof shape of village houses. This skill can be created by seeing construction methods in other villages or by attending professional architecture in the village or due to the passage of time and repetition and practice. Construction problems with local materials such as the lack of highly skilled architects to build the arch, as well as the lack of knowledge about the methods of strengthening earth buildings and of course the long process of traditional roof construction compared to new methods are other reasons for reduction.

In addition to the above, unfortunately, the new government constructions in the villages have also encouraged the villagers to build in non-native ways (Figure 22).

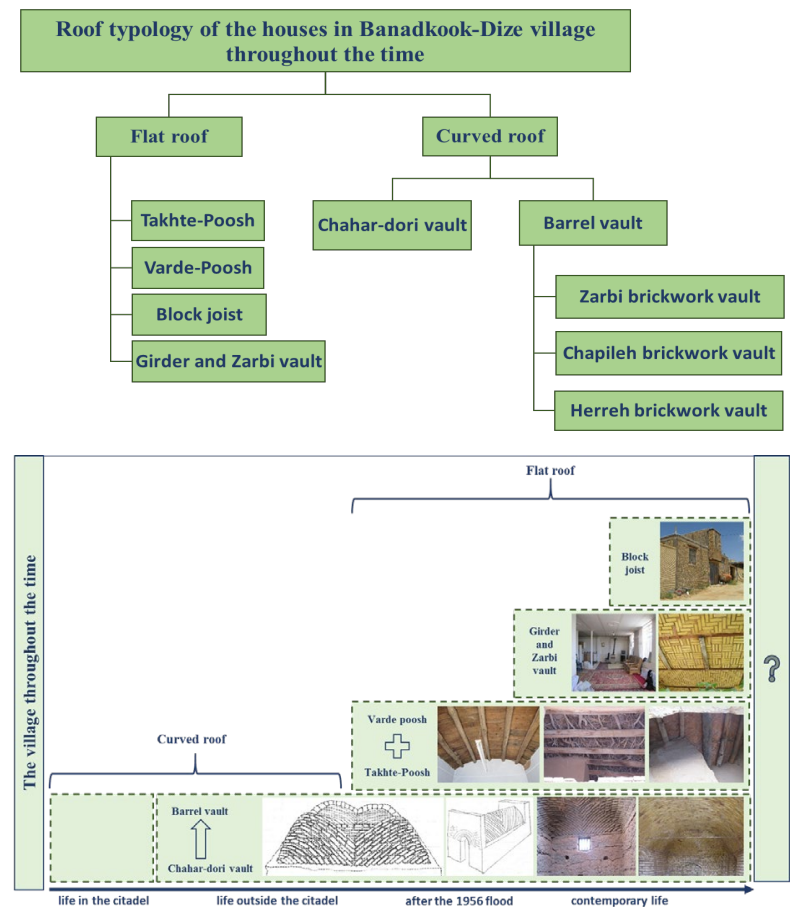

Figure 22. Roof typology of the houses in Banadkook-Dize village throughout the time, author. 


\section{REFERENCES}

Ayatizade, Gholam hossien. 1956. The Black Flood in Taft Yazd. Manuscripts. Personal archive.

Anderson, Graham, 1991. Sharjah, U.A.E.: the urban conservative dilemma, Durham theses, Durham University. Available at Durham E-Theses Online: http://etheses.dur.ac.uk/5993/

Bromberger, Christian. 1988. "Bannā'î" Encyclopædia Iranica, Vol. III, Fasc. 7, 709-712, available online at http://www.iranicaonline.org/articles/bannai-construction.

Ebrahimi, Elmira, Mir-Mousa, Aniran. 2015. Tavizeh, from Structure to Stability Achievement. Current World Environment Vol. 10, 363-373.

Hejazi, Mehrdad and Fatemeh, Mehdizadeh Saradj. 2014. Persian Architectural Heritage: Structure. WIT press, UK.

Kleiss, Wolfram. 2011. "Construction Materials and Techniques in Persian architecture" Encyclopædia Iranica, Vol. VI, Fasc. 2, 217-219, available online at http://www.iranicaonline.org/articles/construction-materialsand-techniques-in-persian-architecture.

Kleiss, Wolfram. 1990. "Castles” Encyclopædia Iranica, Vol. $\mathrm{V}$, Fasc. 1, 65-70, available online at http://www.iranicaonline.org/articles/castles

Minke, GerontGernot. 2006. Building with earth (design and technology of sustainable architecture). Berlin: Birkhauser

Memarian, Gholam hossien. 2015. The basis of architectural design. Naqme No-andish. Tehran.

Memarian, Gholam hossien and Safayi pour, Hadi. 2016. Iranian Architecture (Niaresh). Naqme No-andish. Tehran.

Naghsh-e Raz-e Boom. 2007. Banadkook-Dize guidance plan. Housing Foundation of the Islamic Revolution of Yazd Province.

Nomination 1506, 2016. Document of The Persian Qanat. World heritage list. UNESCO.

Nomination 1544, 2017. Document of Historic City of Yazd. World heritage list. UNESCO.

Pirnia, Karim. 1995. Vaults \& Chefeds, journal of Athar, 24:15.

Pakcheshm, Mozhgan. 2016. Rural Housing redesign whit with an emphasis on contemporary-ization of body construction process. M.A. Thesis. Yazd University, Iran.

Sadat Etezadi, Zahra and Rahimi Ariaei1, Afrooz. 2015. The methodology of Iranian curved arches (Sagh) based on their geometry. Journal of Applied Environmental and Biological Sciences. Vol. 5, 648-662.

Sartipipour, Mohsen. 2012. Rural Housing in Iran: Past, Present, and Future, Architecture Research, 2 (1), 1-12. doi: 10.5923/j.arch.20120201.01. 